\title{
Real-world problem-based learning: a case study evaluated
}

\author{
M R de Villiers* \& D R Queiros \\ University of South Africa \& University of Hertfordshire, UK
}

\begin{abstract}
This article describes and evaluates a case study of a postgraduate practical learning event in the Department of Tourism Management at the University of Pretoria. It involved a real world situation and departed significantly from tradi tional learning, as it bridged the gap between theoretical class learning and professional prac tice. The Hexa C Metamodel is used as inquiry tool to evaluate the student project according to contemporary learning and instructional theories, using the criteria of Creativity, Collaborative learning, Customisation, Components, Cognitive learning, and Constructivism. Background to the particular course is provided followed by a description of the context and scope of the project. This is followed by the research design and the findings of this qualitative evaluation. The article provides valuable insights into the value, challenges, and practicalities of designing and implementing real world practical projects as part of the higher education learning experi ence.
\end{abstract}

\section{INTRODUCTION}

$\mathrm{T}$ here is an increasing trend in tertiary education for practical work to occur within authentic real world situations. Synergistically, this provides mar ket oriented career benefits to learners, valuable publicity for the academic department, and value to the "client" organization. Students' input may also be recognized with credibility, and aspects of their work used. Such partnerships have been described by O'Brien (1999) and Davies \& Pillay (2000). ' Heath (2001)1 terms them "win win" situations, where spin offs attained by learners go beyond the worth of formal academic scenarios.
Traditional education entails single discipline direct instruction, characterized by inter learner competi tion. Real world academic projects, by contrast, are typically multi disciplinary events demonstrating pro blem based learning, constructivist learning and collaborative work. They encourage negotiation and reflection, providing a taste of professional develop ment leading learners toward "reflective practice" (Schon 1987).

This article describes and evaluates a case study as part of the University of Pretoria's postgraduate Ecotourism course. Background is provided by out lining the Ecotourism discipline and describing the context and scope of the project. The research design is then given, and the findings presented of a qualitative evaluation of the learning event from the viewpoint of contemporary learning theory.

\section{BACKGROUND}

\section{Ecotourism}

The UP Department of Tourism Management offers a course called "Ecotourism: Principles and Practices" for honours and masters students in a wide range of fields such as environmental disciplines, sociology, landscape design, and tourism management. Ecotour ism, in itself, is a multi discipline. The course consists of contact sessions plus fieldwork. Classes involve high learner participation and discussion. During the practical collaborative project, learners apply analysis and interpretation to solve a real problem. Ecotourism is defined as:

- enlightening, interactive, participatory travel ex periences,

- to natural and cultural environments,

- making sustainable use of resources,

- providing economic opportunities for industry and local communities, and

\section{Contact person}

Mrs MR de Villiers, Dept of Computer Science, University of South Africa, PO Box 392, Unisa, 0003

Tel (012) 4296559

Fax (012) 4296817

e mail dvillmr@unisa ac za 
- implementing sound environmental management (Adapted from Hattingh 1996, cited in Queiros 2000b).

The ecotourism tetrahedron model (Figure 1) shows the interrelationships and undergirds the theoretical and practical components of the course. The founda tional resource base can be natural or cultural with sustainable usage being key. Local communities should be integrally involved and aspects of their culture reflected in tourism offerings. The ecotourist requires an interactive, enlightening experience more so than traditional tourists. Finally, the ecotour ism industry plays a coordinating pivotal role (Queiros 2000a).

\section{Figure 1}

The ecotourism tetrahedron

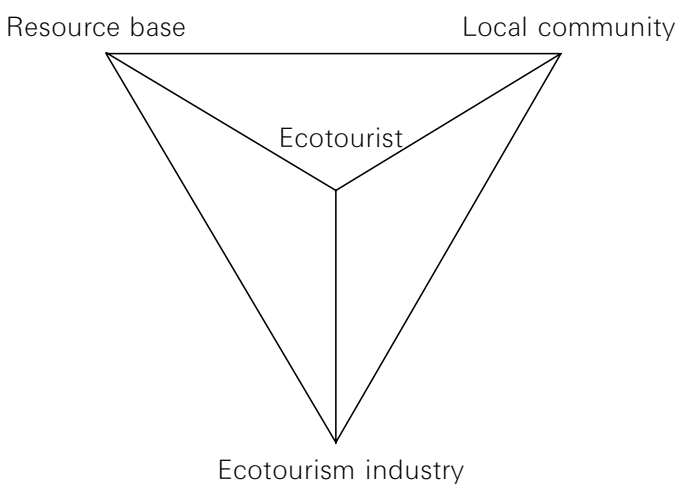

Source: Adapted from Bewser \& Hattingh (2000) in Queiros (2000b)

\section{Context and role-players}

Problem driven, not subject driven, this venture merged environmental sciences with economic and manage ment sciences. Twelve students spent a week at the remote Mkambati Nature Reserve in the Eastern Cape, investigating future development and compiling eco tourism planning guidelines, for academic purposes and for submission to authorities. Learners' backgrounds comprised ranging disciplines and varying expertise.

To manage such projects, course leaders must believe in the concept, design and guide activities, and motivate learners the lecturers served therefore as facilitators. A Unisa researcher joined the fieldtrip as an observer participant, helping with logistics. She later evaluated the venture, surveying student parti cipants and interviewing the leader.

\section{Problem and task}

Mkambati Nature Reserve falls within the Wild Coast SDI (Spatial Development Initiative). Characterised by pristine coastal grasslands and estuarine topogra phy, it is a secluded paradise with natural attractions including waterfalls, gorges, swamp forest, beaches, and fauna. Visitors are mainly naturelovers and fish ers. Both conservation and tourism are managed by provincial nature conservation officials facing:

- Restricted budgets;

- Management and conservation of fauna and flora, including unique species;

- Poaching;

- Poor access, decayed facilities and bureaucratic maintenance procedures:

- Accommodation and hospitality issues which they would prefer to privatize;

- Barriers to privatisation out source companies require profitability/guarantees;

- Unrealistic benefit expectations by local commu nity; and

- Unresolved tourism policies and withdrawal of state funding for research to counteract which, the provincial conservation department is building research partnerships with tertiary institutions, encouraging postgraduate programmes/theses.

The UP Ecotourism students integrated theory and practice as they addressed the question: How best can viable ecotourism be promoted and a fragile environ ment preserved? In four groups, they investigated: (i) fauna and flora; (ii) ecotourist activities; (iii) culture and community; and (iv) accommodation and facilities.

\section{Fieldwork}

The learners observed the intricacies and nature of ecotourism first hand. They enjoyed ecotourist activ ities such as canoeing, hiking, game viewing, swim ming in sea and rivers; and exploring gorges and waterfalls, on site mission churches and a shipwreck.

\section{Real-world status}

Nature conservation authorities regarded the project as more than an academic exercise. The reserve manager outlined Mkambati's heritage and its pro blems and fieldrangers took students around the reserve. The regional director met them, sharing issues and stressing the importance of research. He showed the group a successful community based ecotourism venture on neighbouring tribal land a pilot project for sustainable tourism. Stakeholders (locals and the EU funded NGO) described this venture and demon strated their low impact bushcamp.

A joint approach to resource management, entailing public private partnerships, is viewed as the way forward for Mkambati. National government had provisionally awarded an external tender for Mkam bati's tourism and accommodation services. Due to complications, including community tensions, ne gotiations broke down and the successful bidder 
withdrew. The future of the reserve was once again uncertain. The students were thus exposed to different management models and perspectives. The community aspect was particularly complex involving grievances, claims and benefits, and identifying which locals comprised the "commu nity". The region was topical news, and the fieldtrip coincided with a television producer visiting, who filmed activities and interviewed students featuring their study in national programmes.

With this background, serious work commenced. Evenings were spent on briefing sessions and discussions. Charts and maps covered the walls. Initially students worked alone, studying notes, journals, and documention regarding Mkambati. Groupwork then commenced using maps and laptops, theory was applied, ideas assimilated, di lemmas debated. Which compromises were prag matic ... which were dubious? How to both promote and preserve heritage? Nature of the accommoda tion? Type of tourist? Economic viability? Where should vehicles be permitted? Type of activity? Rationales were converted into contributions. Back in Pretoria, integration and write up continued. Two months later drafts were submitted to the lecturers, marked up, and returned for further work. This refinement beyond the norm for student projects was necessary since the authorities had requested copies. Finally, the facilitator consolidated the docu ment for submission.

\section{THE EVALUATION}

\section{Research design}

This article evaluates the Mkambati Project for its value as a learning event. Descriptive data was generated by qualitative ethnographic research. The researcher participated personally in the exercise, obtaining observational information. Primary data collection was a qualitative non experimental survey

a questionnaire completed by the participants (see Appendix) and interviews. Data is not statistically analyzed nor are percentages given, due to the descriptive nature and small population. Table 1 profiles the learners.

Table 1

Learner population $(n=12)$

\begin{tabular}{|l|l|c|l|c|}
\hline Gender & Female & 5 & Male & 7 \\
\hline Full/part time & Full time & 8 & Part time & 4 \\
\hline Qualifications & $\begin{array}{l}3 \text { rd level } \\
\text { degrees }\end{array}$ & 8 & $\begin{array}{l}\text { Honours/ } \\
\text { 4th level } \\
\text { degrees }\end{array}$ & 4 \\
\hline Ethnicity & White & 9 & Black & 3 \\
\hline
\end{tabular}

\section{Research instrument}

The project is evaluated using as inquiry tool the Hexa C Metamodel (HCMm) (de Villiers 1999; 2000; 2001), which investigates application of contemporary learning and instructional theories. The HCMm framework comprises six inter related elements: three practical characteristics, (1) Creativ ity and motivation (2) Collaborative learning and (3) Customization which are examined first to set the scene; and three theoretical elements, (4) Compo nents (5) Cognitive learning and (6) Constructivism. The findings are based on survey data and heuristic evaluation.

\section{Creativity and motivation}

Aspects used to examine creativity and motivation in a learning environment/event are, for example, Dick's (1995) conditions for creative instruction. Features appropriate to the Mkambati Project are matching of learner interests, motivation, and in novation. In an instructional context, creativity is related to motivation engaging learners; and also to affective aspects attitudes/values of learners as they persevere.

As students interacted, they grasped the sensitivity of the issues. Motivated by the realisation that their combined expertise could benefit the situation and impact on the elements of the ecotourism tetrahedron, they aimed for a balanced approach towards the preservation of fragile, pristine topography, enhance ment of quality of life for locals, while simultaneously realizing returns for the tourism industry and fulfilling experiences for ecotourists.

Initially they viewed the event as an academic exercise, not expecting to practice the art of reflective practitioners (Schon 1987). However, it was gratify ing to find that authorities regarded them with credibility and anticipated their report as a decision making aid. Media programmes featured their activ ities and investigation. This project was not a simulation it was real world, real life and generated high levels of intrinsic motivation. Personal involve ment made them passionate about Mkambati, in creasing the relevance of generating appropriate planning guidelines. Evening discussion sessions included vigorous debate encouraging learning as students wrestled with complex issues and inter related variables. They had to make value laden judgments, interpret the dynamics of the situation, and determine their own beliefs.

Open ended responses to Questions 3.1 and 3.2 in the learner survey (see Appendix) showed that certain students were motivated by the natural environment and others by the opportunity of input into a real life situation. Table 2 on the next page, sets out views and comments on motivation, creativity, 
Table 2

Motivation, creativity and innovation

\begin{tabular}{|c|c|c|c|}
\hline \multicolumn{2}{|l|}{ What motivated you } & \multicolumn{2}{|c|}{ No of students } \\
\hline $\begin{array}{l}\text { Recommendations } \\
\text { regarded with cred } \\
\text { ibility }\end{array}$ & $\begin{array}{l}\text { Our input might be used/market oriented exercise/economic and } \\
\text { social benefits for stakeholders/chance to influence future devel } \\
\text { opments/solve a real world problem/management took us ser } \\
\text { iously }\end{array}$ & \multicolumn{2}{|l|}{8} \\
\hline \multirow{4}{*}{$\begin{array}{l}\text { Presentation of the } \\
\text { natural environment }\end{array}$} & Potential as ecotourism destination/adventure! & 4 & \\
\hline & Experiencing the community where ecotourism was a reality & 2 & \multirow{3}{*}{11} \\
\hline & $\begin{array}{l}\text { Unique beauty/desire to maintain pristine surroundings/captivated } \\
\text { by scenery/passion for the environment/my attitude to nature } \\
\text { changed }\end{array}$ & 4 & \\
\hline & Seeing the sea swimming! (first time for some) & 1 & \\
\hline $\begin{array}{l}\text { Academic motiva } \\
\text { tion }\end{array}$ & $\begin{array}{l}\text { Prospect of high quality product, good marks, bursaries, co } \\
\text { authoring publication }\end{array}$ & \multicolumn{2}{|l|}{1} \\
\hline Challenge! & Flabbergasted by complexities/frustrated by problems & \multicolumn{2}{|l|}{2} \\
\hline \multicolumn{4}{|c|}{ What did you find innovative? } \\
\hline \multirow[t]{2}{*}{ Nature of the project } & $\begin{array}{l}\text { Kind of problem we will encounter in a country in state of } \\
\text { transformation/tourism from ecotourism perspective/marketing } \\
\text { not just tourism, but an ecotourist destination/Need to develop } \\
\text { sustainable ecotourism }\end{array}$ & 5 & \multirow[t]{2}{*}{7} \\
\hline & Real project/practical value/product was a professional document & 2 & \\
\hline \multirow[t]{3}{*}{$\begin{array}{l}\text { Nature of the learn } \\
\text { ing }\end{array}$} & $\begin{array}{l}\text { New way of thinking/integration/developed an open minded } \\
\text { approach/personal experience of problem not just a scenario }\end{array}$ & 5 & \multirow{3}{*}{10} \\
\hline & Discussion and debate between class members & 2 & \\
\hline & $\begin{array}{l}\text { New comprehension bridged the gap between class knowledge } \\
\text { and a real world situation/application: theory practice }\end{array}$ & 3 & \\
\hline \multicolumn{2}{|c|}{$\begin{array}{l}\text { Helped us to be creative and innovative ourselves/Learned to think laterally/Chance to } \\
\text { use theoretical knowledge along with creative faculties to try and solve real problems and } \\
\text { propose innovative tourism guidelines. }\end{array}$} & \multicolumn{2}{|l|}{4} \\
\hline
\end{tabular}

and innovation in the learning event. Learners' own creativity was fostered by a creative experience.

One comment dealt with extrinsic motivation for high grades. Most related to intrinsic motivation: "I found it innovative to do a project of practical use. Students' practical work usually retains an element of amateur ism and adds little value .... Developing market style presentations was unusual for most of us. We could have simply presented an academic treatise (like our first draft), but we reworked it to a final report which was a quality consultant type document."

Motivation changed over the duration (Question 3.3). Prior to the trip there was general keen anticipation. During fieldwork, the affective cognitive connection was firmly in place all students were positive and personal participation encouraged them to persevere diligently. A representative comment was: "A well structured experience ample opportunity for absorb ing the essence of the reserve, as well as time for discussion and reflection. I felt interested and en grossed at all times."

During write up time, conflicting emotions emerged. Motivation decreased. Six learners described the chal lenge of applying theory practically in a real life situation as a positive experience and enjoyed writing guidelines in a way that was realistic and meaningful. Others found enthusiasm waning, citing the complexity of the situa tion; boredom with the problem; and frustration due to the time expended which impacted on other obligations. 
Preparing reports and recommendations for ultimate submission was a major task. Deadlines and high quality are part of real world pressure, where there is a tangible incentive, namely, remuneration! However, real world learning experiences cannot exact real world deliverables without offering some personal benefits. In the case of the Mkambati Project, the benefit was acquisition of market oriented expertise.

The academic worth of this innovative venture was high. A hypothetical exercise is unlikely to lead to the same level of learning and retention, quality of deliverables, and preparation for consulting as this venture with real world dynamics, variables, and complexities.

\section{Collaborative learning}

"Collaborative learning" (Panitz 1996) refers to learners working jointly on a problem. It is learner centric and ties into social constructivism, with an ethos that respects individual contributions in a context of consensus building. Tasks are open ended, whereas those undertaken in co operative learning may be more directive and instructor centric, involving closed problems and predictable solutions. Groupwork in the Mkambati Project was distin guished by its meta collaborative nature a group of groups producing parts of a whole.

Communication skills and problem solving abilities played key roles, as learners worked on the four topics. They chose the one they preferred, the proviso being three per group. Each topic required expert knowledge, research and analysis, complementary capabilities, and a written report with guidelines.

Open ended questions provided rich qualitative data. Responses to Question 5.1 were mainly positive, as learners recognized the integration of diverse dis ciplines and complementary skills, and acknowledged that individual efforts affect group performance. Spontaneous comments are classified under some of Johnson and Johnson's (1991) key elements of co operation:

\section{- Empowerment of individual learners}

“... unique, because we came from very different backgrounds, and classmates ... broadened our view ..."/"We had good discussions and debate ..."/"We delegated tasks, then peer reviewed our performance in brainstorms."

\section{- Positive interdependence}

"Teamwork responsibility makes you work harder, because what you do affects others." /"Our schedules and deadlines were met and each recommendation was a product of three minds." /"We could each do something we are good at!"
“I grew up in a culture that emphasizes individualistic learning and achievement. This contradicts the spirit of teamwork. But now I understand and appreciate the value of groupwork. It allows active involvement. We could be creative and it culminated in multifarious ideas, contributed by students of diverse cultural backgrounds."

"Non performance by one can jeopardize overall quality." /"I struggle with time management and operate by crisis management, so I probably don't give my best, which was tough on my team." /"Some pull their weight more than others." /"Difficult to integrate contributions." " YYou need a good, enthu siastic leader."

\section{- Joint accountability}

There were reservations regarding joint accountability and team marks (Question 5.2): "Joint accountability works when you can ... hold others accountable ... to meet obligations on time and to quality. As students, no one had that authority over another." /"I strongly disagree with a joint mark!" /"Peer review would help marking others on participation and input, as part of final mark." /"University teamwork is preparation for the real world."

Some prefer working alone:

"Joint accountability ... gets in the way of own ership."

Eight of the twelve appreciated collaborative work, but some problems were described. Six students felt that not all had put in equal efforts. Remedies were suggested: "It would be useful if in the planning stages, groups discuss their procedures and set norms, what to do if someone misses deadlines, and what standards to set."

There were impromptu comments about meta colla boration. One felt restricted and would have liked to contribute to other groups. Another stated pertinently: "I wanted to know more about the work of other groups. We should possibly have as a class discussed each section in brainstorming sessions ...."

The evaluation revealed complexities, particularly unequal efforts. Highly committed students objected to efforts that might impact on the documents or their own grades, so they compensated to ensure quality. Peer and self evaluation as part of individual grades could alleviate this. Controversial aspects of team work are, however, a foretaste of the working world. Regarding meta collaboration, the facilitator had a major task in integrating the four reports into one integrated, consistent document, so that proposals did not duplicate, infringe upon or contradict others.

The project capitalised on heterogeneous strengths. 
Complementary skills, serious efforts and the facil itator's work in preparing the unified document, resulted in an end product with utility. The provincial authorities expressed appreciation and placed it on their intranet, stating that it contained aspects which would likely be incorporated into the Mkambati management plan.

\section{Customization}

Learning is customized when individuals use a learning event to learn effectively in a personally optimal way. Customization occurred as learners found roles in their groups, using their varying skills and interests proposal formulation, report writing, photography, computer skills, and subject matter expertise. Diversity contributed to personal fulfillment scope for history, culture, adventure tourism, conservation, management, and hospitality aspects. Furthermore, there are those who choose a field of study due to a passion. Certain students take Ecotourism so as to apply their personal vision and values regarding issues such as environment and community.

Goals were negotiated students could decide on resources for their research, and content of docu ments and final guidelines. Neither facilitator nor learners initially realised the extent of work required to develop products for real world presentation. How ever, the extra work resulted in higher marks and all four groups earned distinctions.

Table 3 shows responses to Questions 4.1 and 4.2, indicating how the learning event matched prefer ences. Students particularly enjoyed debating and pursuing their own ideas.
Other pertinent issues were raised:

- Preparation for future:

"Consultations with management, were good training for ... employment." /"We had to do our own research we really did learn."

- Authentic problem solving:

"... logical, deductive problem solving; review ing all aspects and pros and cons"/ "We were exposed to what really happens and contrasted it with the textbook model." "I have empathy with disadvantaged communities ... this is a real chance to make a difference and contribute to upliftment and work ethic."

- Real world complexities

"The culture and community group struggled with complexities in uncharted territory."

Ten experienced the project as learner centred (Question 4.4).

By delegating responsibilities, each team demonstrated technical competencies. Table 4 indicates software tools used (Question 4.3) to manipulate, integrate and present information, and as aids in problem solving, decision making, and communication.

Customized learning in this event was not implemented in the traditional way by learners doing own choice/ sequence/quantity, etc of predefined activities, but rather by participants finding personal roles in a team customization in the context of collaboration. Further more, the event provided opportunities to build on value systems and personal visions. A learner described the project as "mutualistic", in that the problem gave students practical learning experience, and on the other hand, the results held utility for the "client".

Table 3

Preferences, and how the experience matched personal interests/expertise

\begin{tabular}{|l|c|}
\hline \multicolumn{1}{|c|}{ Comment } & No of students \\
\hline Hands on practical application/theory to practice & 4 \\
\hline $\begin{array}{l}\text { Opportunity to contribute own ideas/personal interpretation/work in my own way/ } \\
\text { freedom to express opinion/we decided on content }\end{array}$ & 7 \\
\hline Enjoy discussion/brainstorming/interaction/negotiation & 4 \\
\hline Could use my subject matter expertise/chose a group that interested me & 6 \\
\hline
\end{tabular}

Table 4

Software packages used

\begin{tabular}{|c|c|c|c|c|c|c|}
\hline $\begin{array}{c}\text { Word } \\
\text { processor }\end{array}$ & Database & $\begin{array}{c}\text { Spread } \\
\text { sheet }\end{array}$ & E mail & $\begin{array}{c}\text { World Wide } \\
\text { Web }\end{array}$ & $\begin{array}{c}\text { Graphics } \\
\text { Packages }\end{array}$ & Other \\
\hline 10 & 2 & 2 & 7 & 9 & 4 & $\begin{array}{l}2 \text { (Power point; } \\
\text { CD presentation) }\end{array}$ \\
\hline
\end{tabular}




\section{Components}

The "component" element of the HCMm relates to rudiments of content. During the Mkambati Project no basic components of theory/knowledge/skills were explicitly communicated, and no survey ques tions relate to components. As a practical application, it was beyond components.

The building blocks/components of ecotourism pre ceded the event, having been presented and dis cussed in class by the facilitator, domain experts, practitioners, and students themselves. Furthermore, basic information about the reserve and its situation were communicated in multi format: verbal, textual, graphical (maps), and visual (slide show). Students were thus equipped with (1) rudiments of ecotour ism; (2) subject specific knowledge from their former fields of study, and ready to contextualise, integrate and consolidate.

\section{Cognitive learning}

An investigation of "cognitive learning" should examine how new knowledge is integrated with prior learning, how gaps are bridged, how learners plan, self regulate and develop critical thinking skills.

\section{- Integration of new with prior knowledge}

Acquisition of advanced knowledge is sometimes founded on basics in the same domain, and sometimes entails content in a different, but associated, domain. The students did both. They extended their specialised expertise by applying it in a multi disciplinary project. but also integrated further contextualised ecotourism knowledge on a just in time basis, reorganizing their internal knowledge structures.

\section{- Bridging, integration and cognitive processing}

Describing prior learning (Question 2.1), students compositely listed varied expertise that was applied and integrated into the ecotourist framework, namely, knowledge of:

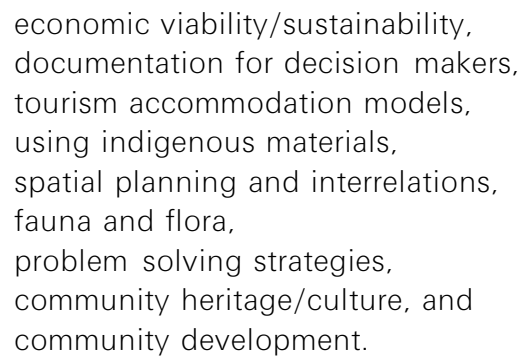

Learning gaps (Question 2.2) were bridged by con sulting library/Internet resources, asking questions, or were resolved naturally during the experiential learn ing. Direct interaction with the resource base and stakeholders stimulated cognitive processing.

\section{- Planning, self monitoring, metacognition}

Groups actively conducted research and were respon sible for their own progress. Question 2.3, relating to self regulation of the learning process, generated six positive views describing pre planning and structured organization, communication, articulation and co ordi nation to achieve consensus, for example: "We knew what was expected to develop a quality product." " "We set a deadline and worked accordingly." /"It depended on self discipline."

\section{- Strategic exploration of errors}

"It allowed us to experiment with our ideas, which were not always correct."

\section{- Cognitive flexibility theory}

Cognitive flexibility theory (Spiro, Feltovitch \& Coulson 1994) is a cognitive constructivist approach concerned mainly with assembling mental schemata. Flexibility theory emphasises transfer of knowledge and skills beyond the initial learning situation, using information from multiple perspectives and diverse case studies. The Mkambati learning event satisfies its main principles:

1. Students encountered multiple representations of content: Information banks were books, class notes and lecturers' expertise, Internet and WWW, maps, consultations with stakeholders, experience, and discussions with co learners (Question 1.3).

2. The content domain was not over simplified: by contrast, complexities and controversies were presented transparently.

3. Case based studies were incorporated: Class lectures featured case studies, with the Mkambati Project itself being a particularly relevant case.

\section{- The cognitive affective connection}

Question 2.4 addresses affective aspects ten students, at times, experienced overload/anxiety. Team production of documents for submission is demanding. Five recorded uncertainty about the depth/detail required. Some wanted to present flexible suggestions, avoiding in depth professional analysis; whereas others aimed for consultant type proposals and specifications. Certain students caused delays, resulting in crisis management. As stated, initially positive attitudes wavered during the pro longed write up.

Learners had to think critically, predicting the im plications for Mkambati of various conceptual mod els, particularly regarding uncharted issues, such as community relations, land rights, and joint use. Further contentious matters, highly debated, were the nature of the accommodation upmarket lodge/ 
resort or low impact eco style and the associated target group. Final proposals were the result of lateral thinking (De Bono 1970) and creative compromises. "challenge applying our minds to issues that are not theoretically conventional".

\section{Constructivism}

The Mkambati learning event is a classic illustration of constructivism. It supports problem based, open ended learning in an ill structured domain. Key features such as active involvement of learners, negotiated solutions, personal interpretation, and collaborative problem solving were present. The authentic real world context of the project has been described. The full week of fieldwork was essential for multi perspective insight into the unique complex ities. Constructivist learning involves active participa tion interpreting and integrating information, then applying it. Learners were encouraged to explore their own ideas, over and above formal content, and in doing so, acquired skills in social negotiation and decision making, leading to proposals based on fundamental ecotourism principles yet accommo dating the system dynamics. The pedagogical ap proach of the event was anchored instruction in an authentic, holistic setting, without simplifying issues. Scaffolding was provided in the form of multiple resources, including previous management proposals.

A further feature of constructivist learning is "learner frustration". The high point of the Mkambati event its real world nature became a source of frustration when it enforced commitment and excellence beyond usual academic efforts.

The multi disciplinary situation complies with proper ties of "ill structured problems" (Jonassen 1999), namely unstated goals and constraints, multiple solu tion paths, multiple criteria for evaluating solutions, uncertainty over which concepts/principles to use, and opportunities to make and defend judgements. When central issues are ill structured, many aspects must still emerge and be defined by learners themselves. Learn ing was "problem based" (Savery \& Duffy 1995) as learners reflectively explored a real situation with potential, yet with complexities, and multiple para meters. It was "problem driven" (Jonassen 1999) as they were exposed to multifacets gaining new conceptual understanding and learning advanced domain content to solve problems and take ownership.

Characteristics of "open ended learning" (Hannafin et al 1994) were evident:

1. Experience was embedded in context experi ences of nature and ecotourist activities; expo sure to problematic aspects; and positive encounters with stakeholders conducting suc cessful ecotourism.

2. Individual mediation of understanding learning was customized encouraging students to contribute according to their interests/abilities.

3. The process was qualitatively different from traditional instruction. Multiple perspectives were provided on a real problem, then theoretical and experiential knowledge were practically applied along with the support of software tools.

Each group moved iteratively from personal inter pretation to product construction. Issues were re visited and initial drafts evolved. Further re construc tion occurred in integrating and moulding the final proposal, as overlaps and inconsistencies were eliminated.

Question 1.1 queried the value of constructivist learning. Elaborations are categorized in Table 5. A learner posited: "The challenge was to work inde pendently in a context with uncertainty, when theory and practice did not correspond".

Table 5

Aspects of constructivist learning

\begin{tabular}{|c|c|c|c|}
\hline \multicolumn{2}{|l|}{ Aspect } & \multicolumn{2}{|c|}{ No of students } \\
\hline \multirow{3}{*}{ Theory to practice } & $\begin{array}{l}\text { Could apply ecotourism theory/combined real scenario with } \\
\text { theoretical background }\end{array}$ & 5 & \multirow{3}{*}{8} \\
\hline & $\begin{array}{l}\text { Applied and explored planning approaches used in tourism } \\
\text { industry }\end{array}$ & 2 & \\
\hline & Creative problem solving & 1 & \\
\hline $\begin{array}{l}\text { Knowledge con } \\
\text { struction }\end{array}$ & $\begin{array}{l}\text { Accommodation of diverse ideas/collectively responsible/Interac } \\
\text { tion was key/highly integrative }\end{array}$ & 5 & \multirow{2}{*}{7} \\
\hline $\begin{array}{l}\text { Collaborative and in } \\
\text { dividual }\end{array}$ & $\begin{array}{l}\text { Active participation/could express own ideas creatively/we used } \\
\text { initiative }\end{array}$ & 2 & \\
\hline III defined aspects & Community relations are beyond conventional theories & 1 & \\
\hline
\end{tabular}


Table 6

Constructivist strengths

\begin{tabular}{|l|l|}
\hline Constructivist feature & \multicolumn{1}{|c|}{ Learners' comments } \\
\hline Multiple perspectives & $\begin{array}{l}\text { Gained broad base of understanding due to: } \\
\text { - Doing research ourselves } \\
\text { - Different viewpoints } \\
\text { - Peers teaching each other. }\end{array}$ \\
\hline $\begin{array}{l}\text { Real world problems } \\
\text { Contextualization }\end{array}$ & $\begin{array}{l}\text { Guidelines may influence future decision makers/deal with problem directly/ } \\
\text { crucial exposure to reality/perspective on complex situation/challenge to } \\
\text { develop new but viable solutions! }\end{array}$ \\
\hline Learner centred & Own opinion has value/could work independently \\
\hline Creativity and innovation & $\begin{array}{l}\text { Helped us develop creative solutions/informed decision making/motivated to } \\
\text { be creative }\end{array}$ \\
\hline
\end{tabular}

Question 1.2 addresses strengths and shortcomings of the experience. Regarding "strengths", students spontaneously mentioned aspects corresponding to key features of cognitive and constructivist philoso phies (Table 6)

The problem drove the learning and concretized the abstract:

"Being on site gave you different perspectives on theoretical jargon"./

"I appreciated exposure to destination specific variables at a unique destination".

Negative aspects were accompanied by remedial suggestions:

- "We need a framework for writing guidelines, and briefing on the kind of information required by decision makers":

- "Pre planning should indicate the extent of work";

- "Evaluation should not be based on team marks"/ "Peer review should contribute to individual marks";

- "Disagreement should be channeled into con structive criticism":

- "Group leaders should instruct and control."

\section{CONCLUSION}

This article has examined the collaborative Mkambati learning event. Findings show that the event was well designed, planned and executed, and that it bridged the gap between theoretical class learning and professional practice. Multidisciplinary ecotour ism entails a range of practical competencies, which were integrated in an holistic and highly constructivist problem solving exercise.

Evaluation, using the Hexa C Metamodel, showed that the Mkambati Project conforms to the ethos of contemporary learning theory. Five elements of the $\mathrm{HCMm}$, namely creativity, customisation, collaborative learning, cognitive learning, and constructivism, were strongly evident, demonstrating close inter relationships.
Value driven learners were intrinsically and extrinsically motivated by the opportunity to do something real, serving as consultants for a "client". When academia becomes real world, high standards are required enforcing additional efforts, yet offering career value.

In a study on capacity building le Grange (2000) proposes that development of future professionals be:

1. Contextual relating to the workplace;

2. Responsive issues explored should be relevant to participants;

3. Emergent with case study work playing a key role;

4. Participatory involving participants in all dimen sions identifying issues, collecting and analysing data, developing and disseminating reports;

5. Critical going beyond activities and appraising underlying values, assumptions and interests;

6. Praxiological explicit merging of theoretical and practical considerations.

The Mkambati Project conformed to all these princi ples as it prepared future professionals to practice the ecotourism discipline.

The questionnaire ended with an open category relating to the perceived worth of the project to individuals and the class. All responses were positive "excellent learning experience"//"invaluable encounters"/"practical expo sure"/"enriching and meaningful".

Four mentioned the value of teamwork, five the theory practice relationship, and five the worth of market oriented, professional development exercises. There is also implicit training in life skills and social develop ment, in line with the values in Reigeluth's (1999) "new", learning focused paradigm, and relevant in multi cultural society, as expressed poignantly by a learner from a formerly disadvantaged group:

Projects of this nature should be highly encouraged. We gained opportunities to:

- know and appreciate one another 
- drive, cook, and eat together

- study and hypothesize together

- hike and swim together, participate together.

It epitomizes the spirit of togetherness and teamwork. I am greatful to the organizers.

To conclude, we suggest the following as success factors for real world academic ventures:

- Facilitators committed to the approach and able to motivate learners;

- Mature learners, who personally believe in the cause/case;

- Incentives usually inherent intangible benefits rather than explicit rewards;

- Sustained motivation recognizing the additional demands and planning for them;

- Small group size if large, subdivide into sub tasks;

- Sub tasks shaped as part of overall project, with linkage maintained from early stages:
- Simplified integration by setting up basic norms/ practices in advance, yet avoiding prescriptive frameworks that inhibit creativity; and

- A combination of team marks and individual grading.

\section{ACKNOWLEDGEMENT}

The authors acknowledge contributions of the participating students and permission from the UP Department of Tourism Management to publish this study.

\section{ENDNOTES}

1 Telephonic communication with Prof E Heath, Head of Department of Tourism Management, UP, October 2001

2 Personal communication with Mr D de Villiers, Regional director, Eastern Cape Nature Conser vation, July 2001.

\section{REFERENCES}

Davies, T A \& Pillay, D 2000. Small, medium and micro enterprise (SMME) partnerships: a tertiary initiative to create a unique co operative education model in commerce (The Business Clinic). South African Journal of Higher Education 14(3):196 203.

De Bono, E 1970. Lateral thinking: a textbook of creativity. Harmondsworth: Penguin Books.

De Villiers, M R 1999. Applying the Hexa C Metamodel of instructional theory and design to educational web applications, in: De Bra, P \& Leggett, J (eds) Proceedings of Web Net 99 World Conference on the WWW and Internet. Honolulu: Association for the Advancement of Computing in Education.

De Villiers, M R 2000. Evaluation of an interactive learning environment: theory and practice. South African Journal of Higher Education 14(3):120 131.

De Villiers, M R 2001. The dynamics of theory and practice in instructional systems design. PhD dissertation, University of Pretoria.

Dick, W 1995. Instructional design and creativity: a response to the critics. Educational Technology 35(4):5 11.

Hannafin, M J, Hall, C, Land, S \& Hill, J 1994. Learning in open ended environments: assumptions, methods, and implications. Educational Technology 34(8):48 55.

Johnson, D W \& Johnson, R T 1991. Learning together and alone. Englewood Cliffs, NJ: Prentice Hall.

Jonassen, D 1999. Designing constructivist learning environments, in Reigeluth, C M (ed) Instructional design theories and models: a new paradigm of instructional theory, Volume /l. Mahwah, NJ: Lawrence Erlbaum.

Le Grange, L 2000. A case study of changing pedagogical practices at a higher education institution. South African Journal of Higher Education 14(1):152 159.

O'Brien, F 1999. Student community research partnerships: a strategy for capacity building. South African Journal of Higher Education 13(3):200 206.

Panitz, T 1996. A definition of collaborative vs cooperative learning. [Online]. Available: http://www.Igu.ac.uk/ deliberations/collab.learning/panitz2.htm

Queiros, D R (ed) 2000a. Ecotourism planning guidelines for Mkambati Nature Reserve. University of Pretoria: Centre for Africa Tourism.

Queiros, D R 2000b. Implementing the fundamentals of ecotourism: the case of Mkambati Nature Reserve, Wild Coast, South Africa. MSc dissertation. University of Pretoria.

Reigeluth, C M 1999. What is instructional design theory and how is it changing? in Reigeluth, C M (ed) Instructional design theories and models: a new paradigm of instructional theory Volume //. Mahwah, NJ: Lawrence Erlbaum.

Savery, J R \& Duffy, T M 1995. Problem based learning: an instructional model and its constructivist framework. Educational Technology 35(5):31 38.

Schon, D A 1987. Educating the reflective practitioner. San Francisco: Jossey Bass Publishers.

Spiro, R, Feltovitch, P \& Coulson, R 1994. Cognitive flexibility theory. [Online]. Available: http://tip.psycholo gy.org/spiro.html 


\section{Appendix}

\section{Section of questionnaire}

1.1 How did you find this experience of constructivist learning? Please describe your emotions honestly.

1.2 Describe both strengths and shortcomings, in your opinion, of this experience of problem based learning they may relate to any aspect or any stage of the project.

1.3 What sources of information did you use: before the trip/at Mkambati/during write up time afterwards?

2.1 Describe how the knowledge and skills required of you in the project related to your own prior learning from previous study.

2.2 Where you lacked prior knowledge, how did you bridge the gap?

2.3 Problem based learning is open ended. It has no fixed endpoint and is flexible in terms of the type and quantity of content. How did you decide how far to take your section of work, and how did it impact on monitoring time, other priorities and obligations, self discipline, etc?

2.4 Did you at any time experience overload and/or anxiety? Please elaborate.

3.1 What motivated you in this learning experience?

3.2 The requirements in this project were innovative and non conventional. Describe what you experienced as innovative, and how you feel about the approach.

3.3 How did you feel about this project and the problem solving approach? For example, did it engross you, hold your attention, stimulate you, or did it frustrate you, bore you, cause you to lose interest, etc? Answer for: before/during the fieldtrip and during write up.

4.1 What are your personal learning preferences? In what way did this experience match/mismatch these experiences?

4.2 Were you able to personalize this learning event to your own particular style, needs, passions, expertise, etc? Please elaborate.

4.3 Which computer systems did you use?

4.4 Did you find the project learner centered? Please explain.

5.1 How did you experience the teamwork? Please elaborate.

5.2 What is your opinion about joint accountability and a team mark? 